\title{
Reasons for Obstetric Scan Among Pregnant Women in Keffi, Nigeria: A Cross-Sectional Study of a Low-Cost Ultrasound Centre
}

\author{
Idris Muhammad Yakubu ${ }^{1} \&$ Srikanta Banerjee ${ }^{2}$ \\ ${ }^{1}$ Public Health, Texila American University, Guyana, South America \\ ${ }^{2}$ College of Health Sciences, Walden University, Minneapolis, Minnesota, United States \\ Correspondence: Idris Muhammad Yakubu, PhD, Public Health, Texila American University, Guyana, South \\ America.
}

Received: November 20, 2020

Accepted: December 25, 2020

Online Published: December 30, 2020

doi:10.20849/ijsn.v5i4.843

URL: https://doi.org/10.20849/ijsn.v5i4.843

\begin{abstract}
Ultrasound is a safe diagnostic tool used in pregnancy to detect significant causes of foeto-maternal mortality. We explored the reasons for an obstetric scan in 400 randomly selected pregnant women attending a low-cost ultrasound centre in Nigeria. We used a cross-sectional analysis using a structured interviewer-administered questionnaire.

The results showed that the participants were aged $27.37 \pm 5.96$ years, $76 \%$ literate, $68.5 \%$ Muslims, $50.5 \%$ small-scale self-employees, and $31.45 \%$ grand-multiparous. The reasons for an obstetric scan were foetal well-being $(44.2 \%)$, referral by a health worker $(34 \%)$, gender determination $(9.7 \%)$, vaginal bleeding $(4.8 \%)$, confirmation of pregnancy $(2.6 \%)$, due-date determination $(2.5 \%)$, foetal weight estimation $(2.1 \%)$, and foetal number $(0.1 \%)$. Spouse education with foetal wellbeing $(p=.001)$, gender determination $(p=.002)$, and dating of gestation $(\mathrm{p}=.002)$; participants' occupation with referral by a health worker $(\mathrm{p}=.026)$ and confirmation of pregnancy $(p=.044)$; spouse occupation with foetal wellbeing $(p=.004)$ and vaginal bleeding $(p<.001)$; daily household income with referral by a health worker $(\mathrm{p}<.001)$ and pregnancy dating $(\mathrm{p}=.005)$; and religion with gender determination $(\mathrm{p}=.007)$. Health education and improved access to ultrasound services will go a long way in improving maternal/child health.
\end{abstract}

Keywords: obstetric ultrasound, pregnant women, maternal health, health disparities

\section{Introduction}

Nigeria is the second country with the worst maternal and child mortalities having daily maternal and under-five deaths of over 145 women and 2,300 children respectively (Odesanya et al., 2015). Globally, Nigeria ranks second with the worst maternal mortality rate of 800 deaths per 100000 live births (Bakari et al., 2015). In Nigeria, emergency obstetric care is available in only 20 per cent of health facilities while skilled birth attendants cover only $35 \%$ of deliveries (Akinyemi et al., 2015).

Antenatal care (ANC) provides an opportunity for pregnant women to have an ultrasound scan. Jing et al. (2015) showed that an obstetric ultrasound could detect most of the causes of maternal death with high specificity and sensitivity. Consequently, Oboro et al. (2015) supported the use of obstetric scan as a tool during ANC for the early diagnosis of some pregnancy-related problems.

Although some studies reported concerns about the safety of obstetric ultrasound (Fowlkes et al., 2008; Shankar and Pagel, 2011; Sheiner et al., 2007), recent evidence did not confirm any significant untoward effects in pregnancy (Bricker et al., 2015; London et al., 2014; Stampalija et al., 2015). This profile makes ultrasound the safest imaging modality in pregnancy. Therefore, ultrasound imaging is widely employed in ANC to mitigate foeto-maternal deaths.

Ultrasound imaging has a high sensitivity and specificity in detecting most of the causes of maternal death (Humphrey, 2016; Milart et al., 2016). This unique property makes it possible for an ultrasound scan to be used as a tool in early diagnosis to enable prompt referral of cases to appropriate health facilities for proper management. Therefore, access to ultrasound services in rural areas can play a significant role in mitigating maternal and child mortalities (Oboro et al., 2015). 
The medical indications for an ultrasound scan in pregnancy depend on the gestational age. In early pregnancy, many studies asserted that confirmation of pregnancy location, viability, duration, and complications were the commonest reasons for an obstetric scan (Kagan et al., 2015). In mid and late gestation, the leading indications are dating, foetal position, wellbeing, growth and malformation, placental condition, and liquor volume assessment (Bakalis et al., 2015; Reddy et al., 2015; Royer, 2015). Postpartum ultrasound can detect retained placenta, uterine rupture, sepsis, and involution, the position of intrauterine contraceptive devices, and assessment and follow-up of congenital malformations (Chapman et al., 2015). Ultrasound is used to inform sophisticated neonatal diagnostic and therapeutic procedures and follow-up (Sananes et al., 2016; Worley et al., 2008).

A growing global non-medical indication for an obstetric ultrasound, especially in developing countries like Nigeria, is determination of foetal sex. This phenomenon could have negative public health implications such as sex selection leading to increased induced or criminal abortions and potential maternal complications including maternal mortality. Inyang-Etoh and Ekanem (2016) demonstrated that about $65 \%$ of expectant mothers preferred to have a male child in their index pregnancy for reasons like inheritance, satisfaction of spouse or spouse family members, and consolidation of marriage. Okeke et al. (2015) asserted that $90 \%$ of primigravidas wanted an ultrasound scan for sex determination and $62 \%$ preferred a male child. Similarly, Larsson et al. (2017) found that $95.8 \%$ of 2289 Swedish women had discussed sex determination with the partner before the ultrasound scan, and $57 \%$ of them and their partners wanted an ultrasound for foetal sex determination.

However, there is a dearth in the literature regarding the precise motivations behind acquiring an ultrasound. In this study we will further investigate if the intention of an acquiring an ultrasound scan is foetal well-being or sex determination, which could lead to sex selection.

\section{Materials and Methods}

The study utilized primary data collected in 2016 using an interviewer-administered questionnaire. The analysis involved descriptive statistics and tests of associations using appropriate statistical tests. A statistical power of $80 \%$, Confidence Interval (CI) of 95\%, Level of Significance of 0.05, and Standard Deviation (SD) of .5 were used for sample size selection to adequately control type I and type II errors (Suresh and Chandrashekara, 2012). Participants less than 18 years of age were excluded on ethical and legal grounds. Random sampling was employed to specifically address selection bias that threatens validity and generalization of findings in cross-sectional studies.

The study used primary data only. These are data in their natural states from original sources that have not been collected before. The survey instrument was an interviewer-administered questionnaire. The questionnaire was suitably designed to produce accurate answers. The research questions satisfied the SMART(er) and FINER criteria (Aslam and Emmanuel, 2010; Riva et al., 2012). They were specific, measurable, achievable, relevant, time-bound, feasible, interesting, novel, ethical, and could be evaluated and revised. They were straightforward and easy to translate into Hausa local language and can be administered by research assistants (Jacobsen, 2014). Additionally, the questions were based on evidence from previous studies and contributions from classmates and the instructor (Farrugia et al., 2010). Finally, the questions could fill in the identified gaps in the body knowledge on the topic (Robinson et al., 2011). The questionnaire had sections on socio-demographics and the reasons for an obstetric ultrasound.

The study was conducted in Hamamah Diagnostic Services Centre (HDSC), Keffi, Nigeria. Keffi is a town 50km from Abuja, the capital city of Nigeria. It is the headquarters of Keffi LGA of Nasarawa State. It is a cosmopolitan settlement because of its proximity to Abuja. HDSC was selected because of its high patronage by pregnant women, the study population of interest that forms a sample frame for recruiting participants. It is the cheapest ultrasound centre in the locality; it charges less than $\$ 2$ per ultrasound scan compared to around $\$ 10$ in other centres in the locality.

The minimum sample size of 384 was selected using a CI of 95\%, Level of Significance of 0.05 , and assumed SD of 0.5. Other methods were not used since the population of targeted pregnant women in rural areas was not known.

Primary data was collected using a structured interviewer-administered questionnaire. The interviewer-administration was chosen to maximize participation. The questionnaire was written in the English language only but translated verbally into Hausa local language where necessary. The approach allowed the participants to brainstorm the questions and establish a rapport (Thompson et al., 2015). It also enabled a quick collection of a large amount of data on several parameters at a low cost. A feasibility study of available medical 
records at HDSC indicated that 400 samples were achievable. Two research assistants were used for data collection only. The data was collected over six weeks during the study period.

The questionnaire had quantitative closed-ended queries that aided a systematic analysis. Firstly, the answers were coded numerically to permit codebook entries. Secondly, the data was directly entered into SPSS. Thirdly, Double-entry was done to ensure data accuracy. Fourthly, the data was cleaned to correct for typographical and other errors. Finally, necessary data re-coding was done during analysis.

The dataset had independent and dependent variables that were nominal, ordinal or continuous. The independent variables were the socio-demographic profile of the participants, while the dependent variables were the reasons for an ultrasound scan. The socio-demographic factors included age, gravidity, education, spouse education, occupation, spouse occupation, daily household income level, and religion.

The analysis initially involved a univariate descriptive analysis using frequencies and percentages to show the distribution of responses with appropriate tables, charts, or graphs. Additionally, measures of central tendency and dispersion were used to analyse the quantitative variables. The socio-demographic factors were tested for possible relationships using bivariate correlation. $\mathrm{X}^{2}$-Test was used for categorical variables and logistic regression to control for confounders.

\section{Results}

The age of the 400 participants ranged from 18 to 45 years with a mean of $27.37 \pm 5.96$ years (Table 1 ). The participants were mostly Muslims (68.5\%), and the remaining 31.5\% were Christians. Most of the women were carrying their second pregnancy, but the gravidity ranged from 1 to 12 with the third pregnancy as the median. Primigravida constituted 15.5\%, Gravida-2 (22\%), Gravida-3 (15.25\%), Gravida-4 (15.8\%), and Gravida-5 and above $(31.45 \%)$ of the respondents.

Table 1. Summary of the socio-demographic characteristics of the participants

\begin{tabular}{llllll}
\hline Demographics & Mean \pm SD & Median & Mode & Minimum & Maximum \\
\hline Age (years) & $27.37 \pm 5.96$ & 26 & 25 & 18 & 45 \\
\hline Gravidity & $3.74 \pm 2.26$ & 3 & 2 & 1 & 12 \\
\hline Education & - & - & SSSC & Not literate & Masters \\
\hline Spouse education & - & - & Diploma & Not literate & Ph.D. \\
\hline Occupation & - & - & $*$ Others & - & - \\
\hline Spouse occupation & - & - & $*$ Others & - & - \\
\hline Income level & - & $<\$ 1.9$ & $<\$ 1.9$ & $<\$ 1.9$ & $>\$ 2$ \\
\hline Religion & - & - & Islam & - & - \\
\hline
\end{tabular}

* Others: Includes small scale Traders, Farmers, Artisans.

The respondents were predominantly literate $(76 \%)$ with a senior secondary school certificate (SSSC) as the commonest highest educational achievement (34.8\%), followed by Islamic education only (20.8\%) and lastly a master's degree $(0.3 \%)$. In contrast (Table 2 ), their spouses had a higher literacy level of $82.2 \%$ with diplomas (28.8\%), SSSC (26.3\%) and a Ph.D. (0.3\%).

The women and their partners were typically involved in small-scale self-employed jobs $(50.5 \%$ against $67.8 \%$ respectively) notably traders $(30.3 \% / 13.5 \%)$, farmers $(15.8 \% / 32.3 \%)$, and artisans $(4.5 \% / 22 \%)$. Unemployment was less prevalent among the respondents (1.5\%) than their spouses $(4 \%)$.

The reasons for an obstetric scan (Table 2) were foetal well-being (44.2\%), referral by a health worker (34\%), gender determination $(9.7 \%)$, and vaginal bleeding (4.8\%). Other reasons included confirmation of pregnancy $(2.6 \%)$, due date determination $(2.5 \%)$, foetal weight estimation $(2.1 \%)$, and lastly foetal number $(0.1 \%)$. 
Table 2. Univariate statistics

\begin{tabular}{|c|c|c|}
\hline \multirow{2}{*}{ Education/Occupation } & \multicolumn{2}{|l|}{ Percentages } \\
\hline & Participants & Spouses \\
\hline \multicolumn{3}{|l|}{ Level of Education } \\
\hline Not literate & $24 \%$ & $18 \%$ \\
\hline Islamic Education only & $20.75 \%$ & $16 \%$ \\
\hline Primary & $6.5 \%$ & $2.25 \%$ \\
\hline JSSC & $3 \%$ & $1.75 \%$ \\
\hline SSSC & $35.25 \%$ & $26 \%$ \\
\hline Diploma & $8.25 \%$ & $28.75 \%$ \\
\hline Highest National Diploma & $1 \%$ & $3.25 \%$ \\
\hline Degree & $0.75 \%$ & $2.75 \%$ \\
\hline Masters & $0.3 \%$ & $1 \%$ \\
\hline $\mathrm{PhD}$ & $0 \%$ & $0.25 \%$ \\
\hline \multicolumn{3}{|l|}{ Occupation of Participants } \\
\hline Unemployed & $1.75 \%$ & $4 \%$ \\
\hline Employed & $4.75 \%$ & $28.50 \%$ \\
\hline Housewife & $43.75 \%$ & $0 \%$ \\
\hline Others & $50.25 \%$ & $67.50 \%$ \\
\hline \multicolumn{3}{|l|}{ Other Occupation } \\
\hline Traders & $30.25 \%$ & $13.25 \%$ \\
\hline Farmers & $15.75 \%$ & $32.25 \%$ \\
\hline Artisans & $4.25 \%$ & $22 \%$ \\
\hline \multicolumn{3}{|l|}{ Reasons for an obstetric scan } \\
\hline Reasons & Frequency & $\%$ \\
\hline Fetal viability or Wellbeing & 322 & $44.2 \%$ \\
\hline Referral for a doctor or health worker & 248 & $34.0 \%$ \\
\hline Gender determination & 71 & $9.7 \%$ \\
\hline Vaginal bleeding & 35 & $4.8 \%$ \\
\hline Confirmation of pregnancy & 19 & $2.6 \%$ \\
\hline Dating of pregnancy & 18 & $2.5 \%$ \\
\hline Fetal weight estimation & 15 & $2.1 \%$ \\
\hline Other reasons (Fetal number) & 1 & $0.1 \%$ \\
\hline Total & 729 & $100.0 \%$ \\
\hline
\end{tabular}

$\mathrm{X}^{2}$-Test revealed statistically significant associations between the socio-demographic variables and reasons for a scan. Gravidity was a predictor of vaginal bleeding $(p=.041)$ and confirmation of pregnancy $(p=.040)$ while the educational level of respondents predicted foetal wellbeing $(\mathrm{p}=.040)$ and referral by a health worker $(\mathrm{p}$ $=.041)$. Similarly, there were associations between spouse education and foetal wellbeing $(p=.001)$, gender determination $(\mathrm{p}=.002)$, and dating of gestation $(\mathrm{p}=.002)$. Occupation was related to referral by a health worker $(p=.026)$ and confirmation of pregnancy $(p=.044)$. Spouse occupation was a determinant of foetal wellbeing $(\mathrm{p}=.004)$ and vaginal bleeding $(\mathrm{p}<.001)$. Daily household income was associated with a referral by a 
health worker $(\mathrm{p}<.001)$ and pregnancy dating $(\mathrm{p}=.005)$. Finally, religion was a predictor of foetal gender determination $(\mathrm{Phi}=.136$, Odds Ratio $[\mathrm{OR}]=2.051, \mathrm{p}=.007)$.

The occupation of the participants was a significant predictor of referral and confirmation of pregnancy as reasons for an ultrasound $(\mathrm{p}<.05)$. The effect size was small in both cases (Cramer's V $[\mathrm{CV}]=.154, \mathrm{p}=.023$ versus $\mathrm{CV}=.164, \mathrm{p}=.013$ respectively). Housewives and other occupations were twice more likely to do a scan because of a referral than the unemployed and employed respondents (Table 3). Housewives were twice more likely to scan for confirmation of pregnancy than women in small-scale self-employed jobs while the employed and unemployed were twice more likely than housewives. The effect was highly concentrated at the employed class (Standardized Residuals $[\mathrm{SR}]=2.4$ ).

Table 3. Associations between socio-demographic variables and reasons for a scan

\begin{tabular}{|c|c|c|}
\hline \multicolumn{3}{|l|}{ Relationships } \\
\hline \multirow[t]{2}{*}{ Occupation vs Referral } & \multicolumn{2}{|l|}{$X^{2}(3, N=400)=9.538, p .023$} \\
\hline & $\%$ Yes (within group) & $\%$ No (within group) \\
\hline Unemployed & $33.3 \%$ & $66.7 \%$ \\
\hline Housewife & $60.0 \%$ & $40.0 \%$ \\
\hline Employed & $35.3 \%$ & $64.7 \%$ \\
\hline Others & $66.8 \%$ & $33.2 \%$ \\
\hline \multirow[t]{2}{*}{ Occupation vs Confirmation of pregnancy } & \multicolumn{2}{|l|}{$X^{2}(3, N=400)=10.803$, p .013} \\
\hline & $\%$ Yes (within group) & $\%$ No (within group) \\
\hline Unemployed & $16.7 \%$ & $83.3 \%$ \\
\hline Housewife & $5.7 \%$ & $94.3 \%$ \\
\hline Employed & $17.6 \%$ & $82.4 \%$ \\
\hline Others & $2.5 \%$ & $97.5 \%$ \\
\hline \multirow[t]{2}{*}{ Spouse occupation vs fetal wellbeing } & \multicolumn{2}{|l|}{$X^{2}(2, N=400)=11.221, p .004$} \\
\hline & $\%$ Yes (within group) & $\%$ No (within group) \\
\hline Unemployed & $56.3 \%$ & $43.8 \%$ \\
\hline Employed & $88.5 \%$ & $11.5 \%$ \\
\hline Others & $78.6 \%$ & $21.4 \%$ \\
\hline \multirow[t]{2}{*}{ Spouse occupation vs Vaginal bleeding } & \multicolumn{2}{|l|}{$\mathrm{X}^{2}(2, \mathrm{~N}=400)=17.299, \mathrm{p}<.001$} \\
\hline & $\%$ Yes (within group) & $\%$ No (within group) \\
\hline Unemployed & $37.5 \%$ & $62.5 \%$ \\
\hline Employed & $7.1 \%$ & $92.9 \%$ \\
\hline Others & $7.7 \%$ & $92.3 \%$ \\
\hline \multirow[t]{2}{*}{ Income vs Referral } & \multicolumn{2}{|l|}{$\mathrm{X}^{2}(2, \mathrm{~N}=400)=15.775, \mathrm{p}<.001$} \\
\hline & $\%$ Yes (within group) & $\%$ No (within group) \\
\hline$<\$ 1.9$ & $66.8 \%$ & $33.2 \%$ \\
\hline$\$ 1.9-\$ 2$ & $56.0 \%$ & $44.0 \%$ \\
\hline$>\$ 2$ & $40.3 \%$ & $59.7 \%$ \\
\hline \multirow[t]{2}{*}{ Income vs Dating } & \multicolumn{2}{|l|}{$X^{2}(2, N=400)=10.733, p .005$} \\
\hline & $\%$ Yes (within group) & $\%$ No (within group) \\
\hline$<\$ 1.9$ & $2.6 \%$ & $97.4 \%$ \\
\hline
\end{tabular}




\begin{tabular}{lll}
\hline$\$ 1.9-\$ 2$ & $8.0 \%$ & $92.0 \%$ \\
\hline$>\$ 2$ & $12.9 \%$ & $87.1 \%$ \\
\hline \multirow{2}{*}{ Religion vs Gender } & & \\
& $\mathrm{X}^{2}(1, \mathrm{~N}=400)=7.367, \mathrm{p} .007$ \\
& $\mathrm{OR}=2.051,95 \% \mathrm{CI}(1.213-3.468)$ \\
\hline Islam & $\%$ Yes (within group) & $\%$ No (within group) \\
\hline Christianity & $14.2 \%$ & $85.8 \%$ \\
\hline
\end{tabular}

Both foetal well-being and vaginal bleeding were significantly predicted by spouse occupation $\left(X^{2}(2, N=400)=\right.$ $11.221, \mathrm{p}=.004$; and $\mathrm{X}^{2}(2, \mathrm{~N}=400)=17.299, \mathrm{p}<.001$ respectively $)$. The impact was more on vaginal bleeding $(\mathrm{CV}=208, \mathrm{p}<.001$ against $\mathrm{CV}=.167, \mathrm{p}=.004)$. The significance $(\mathrm{SR}=2.2)$ lies in the wives of unemployed husbands who were less likely to request a scan for foetal wellbeing than those of the employed (Table 3 ).

The unemployed spouse category had the highest percentage of $37.5 \%$ and other occupation the least. Participants of unemployed spouses were thrice more likely to do a scan for vaginal bleeding than those in the other two categories. The difference was in the unemployed category $(\mathrm{SR}=3.9)$.

Daily household income as a measure of poverty was significantly related to referral by a health worker and dating of pregnancy. The $\mathrm{p}$ values were very low in both cases $(\mathrm{p}=.001-.005)$ but the effect size small $(\mathrm{CV}=.185-.199, \mathrm{p}=.001)$. The percentages of referrals increased down the ladder of income level (Table 3). Both effects were concentrated around those households living above poverty line $(\mathrm{SR}=2.8$ versus 3.1 respectively). The likelihood of scanning for dating pregnancy increased with a rising income level.

There was a significant relationship between religion and doing a scan for gender determination $\left(X^{2}(1, N=400)\right.$ $=7.367, \mathrm{SR}=2, \mathrm{OR}=2, \mathrm{p}=.007)$. The effect size was small $(\mathrm{Phi}=.136, \mathrm{p}=.007)$. The percentage of Christians interested in foetal gender determination was $25 \%$ as against $14 \%$ for Muslims (Table 3). The practical implication was that for every probability of Muslims requesting for foetal gender; there was a twice likelihood for Christians. This trend might not be unconnected with male-dominant inheritance practices among Nigerian Christians in a patriarchal society.

With multivariate regression to control for confounding effect, participants' occupation (OR $=.191$, CI $=.051-.718, \mathrm{p}=.014)$ and daily household income $(\mathrm{OR}=3.543, \mathrm{CI}=1.768-7.099, \mathrm{p}<.001)$, religion $(\mathrm{OR}$ $=.494, \mathrm{CI}=.247-.987, \mathrm{p}=.046)$, and spouse occupation $(\mathrm{OR}=6.659, \mathrm{CI}=1.661-26.700, \mathrm{p}=.007)$ were retained as significant predictors of referral by a health worker, gender determination, and vaginal bleeding respectively.

\section{Discussion}

In this study, the main reason for doing an obstetric scan was foetal well-being $(44.2 \%)$, followed by referral by a healthcare worker (34.0\%), gender determination (9.7\%), vaginal bleeding, $(4.8 \%)$, confirmation of pregnancy $(2.6 \%)$, dating pregnancy $(2.5 \%)$, and foetal weight estimation $(2.1 \%)$. This is an important finding because the safety of the foetus is a positive effect of ultrasound screening while sex determination can potentially lead to more harmful practices like sex selection.

These findings are consistent in many respects with previous studies. Enakpene et al. (2009) found foetal viability and foetal gender determination as the key reasons for doing ultrasound in pregnancy. On the other hand, in Ikeako et al. (2014) study, foetal gender determination (17.8\%) and foetal position (15.4\%) were the leading reasons for an obstetric scan. In contrast, Oboro et al. (2015) reported pregnancy confirmation (87.5\%), foetal presentations $(70.3 \%)$, location of pregnancy $(66.8 \%)$, confirmation of miscarriage $(66.6 \%)$, foetal number $(65.3 \%)$, and foetal growth restriction $(60.0 \%)$ as the most common reasons for obstetric scans as described by Nigerian health workers. These differences may be connected with the participants and the study settings. Oboro et al. (2015) targeted health workers, while the other two studies focused on pregnant women in urban areas. However, this study concentrated on pregnant women residing in rural areas assessing low-cost obstetric ultrasound services.

Only $0.1 \%$ of respondents did a scan for foetal number contrary to the findings of Oboro et al. (2015) where $65.3 \%$ of respondents gave foetal number determination as a reason of doing an obstetric ultrasound. This difference might be due to the high incidence of twin pregnancy among the Yoruba ethnicity of the southwest Nigeria (Aduloju et al. 2015), the setting for the Oboro et al. (2015) study. 
Socio-demographic characteristics have been known to influence knowledge, attitude, and practice (Rollins et al., 2016). This study found significant associations between socio-demographic variables and reasons for a scan. Participants' occupation and daily household income, religion and spouse occupation were determined to be significant predictors of referral by a health worker, gender determination, and vaginal bleeding as reasons for a scan respectively. Participants' occupation was a predictor of choosing HDSC because of low cost and quality of service while spouse occupation was a predictor of recommendation by a friend or relative as reasons for choosing HDSC. Age, gravidity, spouse education, religion, participants' and spouse occupation were significantly associated with distance travelled while daily household income level and religion were significant predictors of satisfaction level.

Other studies had established some of these relationships. Enakpene et al. (2009) found that age, occupation, level of education were significant predictors of foetal viability on $\mathrm{X}^{2}$-Test but not on logistic regression. However, in this study educational background of participants and their spouse, and spouse occupation were significant predictors on bivariate analysis with spouse education not retained by logistic regression but retained by hierarchical multiple regression $\left(\mathrm{R}^{2}\right.$ change $\left.=30 \%, \beta=.205, \mathrm{CI}=.016-.059 . \mathrm{F}(1,396)=12.179, \mathrm{p}=.001\right)$.

Foetal gender determination was predicted by spouse education and religion but only religion retained on both logistic regression (Muslims versus Christians, $\beta=-.706, \mathrm{OR}=.494 . \mathrm{CI}=247-.987, \mathrm{p}=.046$ ) and hierarchical model $\left(\mathrm{R}^{2}\right.$ Change $\left.=20 \%, \beta=.141, \mathrm{CI}=.035-.196, \mathrm{~F}(1,397)=7.966, \mathrm{p}=.005\right)$. In contrast, Enakpene et al. (2009) found age, religion, occupation and gravidity as predictors of gender determination on $\mathrm{X}^{2}$-Test while only gravidity and occupation remained statistically significant in the multivariate model. In both studies, Christians were more likely to request a scan for gender determination than Muslims, though none of these studies explored the emerging issue of sex selection abortive practices. The study by Enakpene et al. (2009) did not go further to analyse the predictors of the other reasons, but this study analysed the predictors of all the outcome variables.

The financial burden of foetal gender determination is mostly covered by out-of-pocket payment and not funded by the government or any health insurance schemes. The ultrasound request for foetal gender is prevalent in Nigeria at the expense of serious pregnancy-related risk assessment for due dates, foetal well-being, and antepartum bleeding. This trend prolongs the waiting time for obstetric ultrasound services with reports of massive haemorrhage and even deliveries happening during waiting time (Bindman et al., 1991; Umar et al., 2011). There is a need to address this situation in the light of ethics, morality, cultural norms, and social justice (Ohagwu et al., 2014).

\section{Conclusion}

The study had achieved its objectives of discovering the reasons of seeking ultrasound services by pregnant women attending HDSC Keffi and testing associations between the socio-demographic characteristics of the participants against the reasons for a scan.

The primary reasons for a scan were to assess foetal well-being, foetal gender, and because of vaginal bleeding. Christians were more likely to check foetal gender than Muslims. The association between gravidity and vaginal bleeding calls for the need for governments and non-governmental organizations to provide more support for family planning services to prevent fatal antepartum and postpartum haemorrhage associated with grand multiparity.

The study clearly demonstrated the role of educational level of both pregnant women and their spouses in predicting foetal wellbeing. Improved maternal and spouse education will improve the wellbeing of not only foetuses, but also the general wellbeing of all children, mothers, and the community at large. Hence the need for more campaigns and opportunities for education such as scholarships and grants to disadvantaged populations in fighting foetal and maternal morbidity and mortality.

The association between occupation and referral by a health worker suggests the role of occupational groups in enhancing access to healthcare services. Therefore, public health campaign organizations should involve occupational groups in disseminating health information. Market women in Africa can be used as public health partners in disseminating health information on maternal and child health. Knowledge is empowering.

\section{Acknowledgements}

This study was part of the requirement for the award of Masters of Public Health by the University of Roehampton, London. The authors wish express deep gratitude to the management and staff of Hamamah Diagnostic Services Centre, Keffi, Nigeria for granting permission for the conduct of this study. 


\section{References}

Aduloju, O. P., Olofinbiyi, B., Olagbuji, B. N., Ade-Ojo, I. P., \& Akintayo, A. (2015). Obstetric outcome of twin gestations in a tertiary hospital South-western Nigeria. The Journal of Maternal-Fetal \& Neonatal Medicine, 28(8), 900-904. https://doi.org/10.3109/14767058.2014.937690

Akinyemi, J. O., Bamgboye, E. A., \& Ayeni, O. (2015). Trends in neonatal mortality in Nigeria and effects of bio-demographic and maternal characteristics. BMC Pediatrics, $15(1), 36$. https://doi.org/10.1186/s12887-015-0349-0

Aslam, S., \& Emmanuel, P. (2010). Formulating a researchable question: A critical step for facilitating good clinical research. Indian Journal of Sexually Transmitted Diseases and AIDS, 31(1), 47. https://doi.org/10.4103/0253-7184.69003

Bakalis, S., Akolekar, R., Gallo, D. M., Poon, L. C., \& Nicolaides, K. H. (2015). Umbilical and fetal middle cerebral artery Doppler at 30-34 weeks' gestation in the prediction of adverse perinatal outcome. Ultrasound in Obstetrics \& Gynecology, 45(4), 409-420. https://doi.org/10.1002/uog.14822

Bakari, M., Takai, I. U., \& Bukar, M. (2015). Rising trend in maternal mortality at the university of Maiduguri Teaching hospital. Tropical Journal of Obstetrics and Gynaecology, 32(1), 124-131.

Bindman, A. B., Grumbach, K., Keane, D., Rauch, L., \& Luce, J. M. (1991). Consequences of queuing for care at a public hospital emergency department. Jama, 266(8), 1091-1096. https://doi.org/10.1001/jama.1991.03470080061030

Bricker, L., Medley, N., \& Pratt, J. J. (2015). Routine ultrasound in late pregnancy (after 24 weeks' gestation). Cochrane Database of Systematic Reviews, 2015(6). https://doi.org/10.1002/14651858.CD001451.pub4

Chapman, T., Mahalingam, S., Ishak, G. E., Nixon, J. N., Siebert, J., \& Dighe, M. K. (2015). Diagnostic imaging of posterior fossa anomalies in the fetus and neonate: part 2, posterior fossa disorders. Clinical Imaging, 39(2), 167-175. https://doi.org/10.1016/j.clinimag.2014.10.012

Enakpene, C. A., Morhason-Bello, I. O., Marinho, A. O., Adedokun, B. O., Kalejaiye, A. O., Sogo, K., et al.. (2009). Clients' reasons for prenatal ultrasonography in Ibadan, South West of Nigeria. BMC Women's Health, 9(1), 12. https://doi.org/10.1186/1472-6874-9-12

Farrugia, P., Petrisor, B. A., Farrokhyar, F., \& Bhandari, M. (2010). Research questions, hypotheses and objectives. Canadian Journal of Surgery, 53(4), 278.

Fowlkes, J. B., Abramowicz, J. S., Church, C. C., Holland, C. K., Miller, D. L., O'Brien, W. D., et al.. (2008). American Institute of Ultrasound in Medicine consensus report on potential bioeffects of diagnostic ultrasound: executive summary. Journal of Ultrasound in Medicine, 27(4), 503-515. https://doi.org/10.7863/jum.2008.27.4.503

Humphrey, M. D. (2016). Maternal mortality trends in Australia. The Medical Journal of Australia, 205(8), 344-346. https://doi.org/10.5694/mja16.00906

Ikeako, L. C., Ezegwui, H. U., Onwudiwe, E., \& Enwereji, J. O. (2014). Attitude of expectant mothers on the use of ultrasound in pregnancy in a tertiary institution in South east of Nigeria. Annals of Medical and Health Sciences Research, 4(6), 949-953. https://doi.org/10.4103/2141-9248.144923

Inyang-Etoh, E. C., \& Ekanem, A. M. (2016). Child-sex preference and factors that influenced such choices among women in an obstetric population in Nigeria. Open Access Library Journal, 3(10), e3005. https://doi.org/10.4236/oalib.1103005

Jacobsen, K. H. (2014). Introduction to global health. Jones \& Bartlett Publishers.

Jing, Z., Dan, L., \& Liqing, P. (2015). The characteristics of ectopic pregnancy ultrasound image and value of vaginal ultrasound combined with abdominal ultrasound in diagnosis of ectopic pregnancy. Journal of Hainan Medical University, 161-164.

Kagan, K. O., Wright, D., \& Nicolaides, K. H. (2015). First-trimester contingent screening for trisomies 21, 18 and 13 by fetal nuchal translucency and ductus venosus flow and maternal blood cell-free DNA testing. Ultrasound in Obstetrics \& Gynecology, 45(1), 42-47. https://doi.org/10.1002/uog.14691

Larsson, M., Berglund, M., Jarl, E., \& Tydén, T. (2017). Do pregnant women want to know the sex of the expected child at routine ultrasound and are they interested in sex selection?. Upsala Journal of Medical Sciences, 122(4), 254-259. https://doi.org/10.1080/03009734.2017.1408723 
London, M. L., Ladewig, P. W., Ball, J. W., Bindler, R. M., \& Cowen, K. J. (2014). Maternal \& child nursing care. Pearson.

Milart, P. H., Molina, C. A., Prieto-Egido, I., \& Martínez-Fernández, A. (2016). Use of a portable system with ultrasound and blood tests to improve prenatal controls in rural Guatemala. Reproductive Health, 13(1), 110. https://doi.org/10.1186/s12978-016-0237-6

Oboro, V., Akinmoladun, J., Oboro, O., \& Awopetu, O. (2015). P13. 08: Educational needs of Nigerian health workers for levels I and II obstetric and gynecological ultrasound. Ultrasound in Obstetrics \& Gynecology, 46, 163-164. https://doi.org/10.1002/uog. 15442

Odesanya, A., Hassan, S., \& Olaluwoye, D. (2015). Mass media and maternal healthcare: A critical discourse. New Media and Mass Communication, 34, 63-71.

Ohagwu, C. C., Eze, C. U., Eze, J. C., Odo, M. C., Abu, P. O., \& Ohagwu, C. I. (2014). Perception of male gender preference among pregnant Igbo women. Annals of Medical and Health Sciences Research, 4(2), 173-178. https://doi.org/10.4103/2141-9248.129027

Okeke, T. C., Enwereji, J. O., Okoro, O. S., Iferikigwe, E. S., Ikeako, L. C., Ezenyeaku, C. C., et al.. (2015). Desire for prenatal gender disclosure among primigravidae in Enugu, Nigeria. Patient Preference and Adherence, 9, 429. https://doi.org/10.2147/PPA.S77029

Reddy, A., Malik, R., Mehra, S., Singh, P., \& Ramachandran, L. (2015). Correlation of doppler studies at 34 weeks of gestation with perinatal outcome in high risk pregnancies. International Journal of Reproduction, $\begin{array}{llll}\text { Contraception, Obstetrics and } & \text { 1894-1899. }\end{array}$ https://doi.org/10.18203/2320-1770.ijrog20151282

Riva, J. J., Malik, K. M., Burnie, S. J., Endicott, A. R., \& Busse, J. W. (2012). What is your research question? An introduction to the PICOT format for clinicians. The Journal of the Canadian Chiropractic Association, 56(3), 167.

Robinson, K. A., Saldanha, I. J., \& Mckoy, N. A. (2011). Development of a framework to identify research gaps from systematic reviews. Journal of Clinical Epidemiology, 64(12), 1325-1330. https://doi.org/10.1016/j.jclinepi.2011.06.009

Rollins, N. C., Bhandari, N., Hajeebhoy, N., Horton, S., Lutter, C. K., Martines, J. C., et al.. (2016). Why invest, and what it will take to improve breastfeeding practices?. The Lancet, 387(10017), 491-504. https://doi.org/10.1016/S0140-6736(15)01044-2

Royer, D. (2015). Ultrasound-an essential part of the anatomy educator toolkit?. The FASEB Journal, 29(1_supplement), 692-701.

Sananes, N., Cruz-Martinez, R., Favre, R., Ordorica-Flores, R., Moog, R., Zaloszy, A., et al.. (2016). Two-year outcomes after diagnostic and therapeutic fetal cystoscopy for lower urinary tract obstruction. Prenatal Diagnosis, 36(4), 297-303. https://doi.org/10.1002/pd.4771

Shankar, H., \& Pagel, P. S. (2011). Potential Adverse Ultrasound-related Biological Effects; A Critical Review. Anesthesiology: The Journal of the American Society of Anesthesiologists, 115(5), 1109-1124. https://doi.org/10.1097/ALN.0b013e31822fd1f1

Sheiner, E., Shoham-Vardi, I., \& Abramowicz, J. S. (2007). What do clinical users know regarding safety of ultrasound during pregnancy?. Journal of Ultrasound in Medicine, 26(3), 319-325. https://doi.org/10.7863/jum.2007.26.3.319

Stampalija, T., Medley, N., \& Alfirevic, Z. (2015). Fetal and umbilical Doppler ultrasound in normal pregnancy. The Cochrane Database of Systematic Reviews, 2015(4).

Suresh, K. P., \& Chandrashekara, S. (2012). Sample size estimation and power analysis for clinical research studies. Journal of Human Reproductive Sciences, 5(1), 7. https://doi.org/10.4103/0974-1208.97779

Thompson, F. E., Dixit-Joshi, S., Potischman, N., Dodd, K. W., Kirkpatrick, S. I., Kushi, L. H., et al.. (2015). Comparison of interviewer-administered and automated self-administered 24-hour dietary recalls in 3 diverse integrated health systems. American Journal of Epidemiology, 181(12), 970-978. https://doi.org/10.1093/aje/kwu467

Umar, I., Oche, M. O., \& Umar, A. S. (2011). Patient waiting time in a tertiary health institution in Northern Nigeria. Journal of Public Health and Epidemiology, 3(2), 78-82. 
Worley, K. C., Hnat, M. D., \& Cunningham, F. G. (2008). Advanced extrauterine pregnancy: diagnostic and therapeutic challenges. American Journal of Obstetrics and Gynecology, 198(3), $297-301$. https://doi.org/10.1016/j.ajog.2007.09.044

\section{Appendix}

list of abbreviations

\begin{tabular}{ll}
\hline Abbreviation & Full Meaning \\
\hline ANC & Antenatal care \\
\hline CI & Confidence Interval \\
\hline CV & Cramer's V \\
\hline FINER & Feasible, Interesting, Novel, Ethical, and Relevant \\
\hline HDSC & Hamamah Diagnostic Services Centre \\
\hline LGA & Local Government Area \\
\hline OR & Odds Ratio \\
\hline Ph.D. & Doctor of Philosophy \\
\hline SD & Standard Deviation \\
\hline SMART(er) & Specific, Measurable, Agreed, Realistic, Time-Bound, Evaluated, and Reviewed \\
\hline SPSS & Statistical Package for Social Sciences \\
\hline SR & Standardized Residuals \\
\hline SSSC & Senior Secondary School Certificate \\
\hline
\end{tabular}

\section{Copyrights}

Copyright for this article is retained by the author(s), with first publication rights granted to the journal.

This is an open-access article distributed under the terms and conditions of the Creative Commons Attribution license (http://creativecommons.org/licenses/by/4.0/). 